\title{
Optically-amplified PON system using XGM-based ALC technique
}

\author{
Katsuhisa Taguchi $^{\mathrm{a})}$, Masamichi Fujiwara, Takeshi Imai, \\ Ken-Ichi Suzuki, Hiroshi Ishii, and Naoto Yoshimoto \\ NTT Access Network Services Systems Laboratories, NTT Corporation, \\ 1-1, Hikarinooka, Yokosuka-shi, Kanagawa, 239-0847, Japan \\ a)taguchi.katsuhisa@lab.ntt.co.jp
}

\begin{abstract}
This paper describes an automatic level control (ALC) technique that utilizes cross gain modulation (XGM)-based wavelength conversion to expand the upstream transmission operating areas in optically-amplified passive optical network (PON) systems. We conduct experiments to evaluate the allowable link budgets of opticallyamplified PON systems using XGM-based ALC (XGM-ALC), and also show that we can achieve a large operating area with a dynamic range in a trunk span of $18.5 \mathrm{~dB}$ against an allowable link loss range for an access span of between 8.0 and $20.0 \mathrm{~dB}$. The allowable link loss range of an access span can be expanded to between 8.0 and $25.0 \mathrm{~dB}$ if the dynamic range in the trunk span is reduced to $15.5 \mathrm{~dB}$. A total link budget of $55.0 \mathrm{~dB}$ is achieved.
\end{abstract}

Keywords: PON, SOA, Wavelength conversion, ALC, XGM

Classification: Fiber-optic communication

\section{References}

[1] K.-I. Suzuki, Y. Fukada, D. Nesset, and R. Davey, "Amplified gigabit PON systems," OSA J. Opt. Netw., vol. 6, no. 5, pp. 422-433, 2007.

[2] K.-I. Suzuki, Y. Fukada, K. Saito, T. Nakanishi, and Y. Maeda, "Burstmode optical amplifier for PON application," Proc. ECOC'2005, Th2.3.4, 2005.

[3] N. Suzuki and J. Nakagawa, "First demonstration of full burst optical amplified GE-PON uplink with extended system budget of up to $128 \mathrm{ONU}$ splits and $58 \mathrm{~km}$ reach," Proc. ECOC'2005, Tu1.3.3, 2005.

[4] R. Davey, D. Grossman, M. Rasztovits-Wiech, D. Payne, D. Nesset, A. Kelly, A. Rafel, S. Appathurai, and S.-H. Yang, "Long-reach passive optical networks," IEEE J. Lighw. Technol., vol. 27, no. 3, pp. 273-291, 2009.

[5] M. Fujiwara, K.-I. Suzuki, K. Hara, T. Imai, K. Taguchi, H. Ishii, N. Yoshimoto, and H. Hadama, "Burst-mode compound optical amplifier with automatic level control circuit that offers enhanced setting flexibility in a $10 \mathrm{~Gb} / \mathrm{s}$-class PON," Proc. ECOC'2010, PDP3.2, 2010.

[6] J. Y. Emery, B. Lavigne, C. Porcheron, C. Janz, F. Dorgeuille, F. Pommereau, F. Gaborit, I. G. Neubauer, and M. Renaud, "Increased input power dynamic range of Mach-Zehnder wavelength converter us- 
ing a semiconductor optical amplifier power equalizer with $8 \mathrm{dBm}$ output saturation," IET Electron. Lett., vol. 35, pp. 955-956, 1999.

[7] R. Sato, T. Ito, Y. Shibata, A. Ohki, and Y. Akatsu, "40-Gb/s burst-mode optical 2R regenerator," IEEE, Photon. Technol. Lett., vol. 17, pp. 21942196, 2005.

[8] D. P. Shea and J. E. Mitchell, "Architecture to integrate multiple PONs with long reach DWDM backhaul," IEEE J. Sel. Areas Commun., vol. 27, pp. 126-133, 2009.

[9] IEEE Std 802.3 ah, "Part 3: Carrier sense multiple access with collision detection (CSMA/CD) access method and physical layer specifications,".

\section{Introduction}

Gigabit Ethernet passive optical networks (GE-PONs) and Gigabit-capable PONs (G-PONs) are being used to provide users with cost-effective broadband services. To offer PON-based services more effectively, several research groups have been actively investigating optically-amplified PON systems $[1,2,3,4]$. However, the minimum distance to the nearest optical network unit $(\mathrm{ONU})$ is strictly limited because of receiver overloading caused by the high gain of optical amplifiers, which reduces the dynamic system ranges of optically-amplified PON systems. To solve this problem, we have proposed the application of an automatic level control (ALC) circuit to optical amplifiers consisting of a high-speed variable optical attenuator (VOA) [5].

In contrast, semiconductor optical amplifiers (SOAs) can provide an ALC function through the use of cross gain modulation (XGM)-based wavelength conversion, and XGM-based ALC (XGM-ALC) techniques are often used when studying optical packet switching systems in core networks $[6,7]$. The application of XGM-based wavelength conversion to optically-amplified PON systems is also proposed in [8], however, their investigations do not focus on the effectiveness of the ALC function offered by XGM.

This paper studies an application of the XGM-ALC technique to opticallyamplified PON systems. We verify the effectiveness of the XGM-ALC technique, namely the expansion of the operating areas of optically-amplified PON systems, using experiments to evaluate the allowable loss ranges for both access and trunk spans.

\section{Experimental setup}

Figure 1 shows the experimental setup of the operating area measurement in an optically-amplified PON system using XGM-ALC. We used the $1550 \mathrm{~nm}$ wavelength band in our experiment, however our conclusion can also apply to the $1300 \mathrm{~nm}$ band for upstream signals in PON systems. Our experimental setup consisted of an ONU, an optical amplifier with XGM-ALC and an optical line terminal (OLT). Link A between the ONU and the optical amplifier with the XGM-ALC is defined as an access span that includes an optical splitter and a transmission optical fiber. On the other hand, Link B 


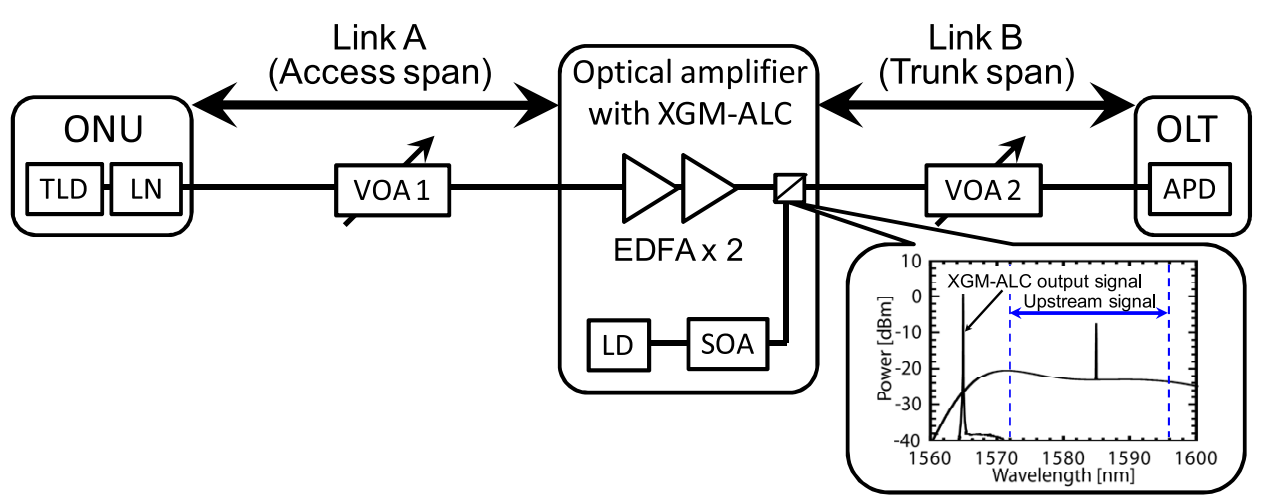

Fig. 1. Experimental setup for measuring operating area of optically-amplified PON systems using XGMALC.

between the optical amplifier and the OLT is defined as a trunk span that only connects transmission optical fiber. The ONU transmitter consists of a wavelength tunable distributed-feedback laser diode (TLD) and an external $\mathrm{LiNbO}_{3}$ intensity modulator (LN). The TLD simulates the wavelength drift of the upstream signals from each ONU owing to the temperature dependence of the un-cooled transmitter. Hence, the oscillation wavelength of the TLD is varied between 1572 and $1596 \mathrm{~nm}$. The LN is operated at $1.25 \mathrm{~Gb} / \mathrm{s}$ with a pseudo random bit sequence (PRBS) pattern of $2^{31-1}$. The output power and extinction ratio of the ONU transmitter are $0.0 \mathrm{dBm}$ and $10.2 \mathrm{~dB}$, respectively. The optical amplifier with XGM-ALC consists of two in-line L-band erbium-doped fiber amplifiers (EDFAs), a C/L-band pass filter, an SOA based XGM wavelength converter and the LD of a probe (wavelength conversion) light source. The gain and noise figure (NF) of the EDFAs are 28.5 and $5.5 \mathrm{~dB}$, respectively. Upstream signals from each ONU are amplified by the EDFAs. The probe light source supplied by a continuous wave $(\mathrm{CW})$ is injected into the SOA in the counter propagating direction of upstream signal. Then, the probe light is modulated with an inverted upstream signal bit pattern by the XGM effect. The injected current and the gain peak wavelength of the SOA are $300 \mathrm{~mA}$ and 1584 to $1598 \mathrm{~nm}$, respectively. The probe light power and converted wavelength are adjusted to $4.2 \mathrm{dBm}$ and $1565 \mathrm{~nm}$, respectively, which provide the maximum ALC effect at each upstream wavelength. The amplified upstream signal and XGM-ALC output signal are multi/demultiplexed by a $\mathrm{C} / \mathrm{L}$-band pass filter. The OLT consists of a $1.25 \mathrm{~Gb} / \mathrm{s}$ avalanche photodiode (APD) receiver with a sensitivity of $-33.5 \mathrm{dBm}$ at bit error rate (BER) of $10^{-12}$, and detects the XGM-ALC output signal. In our experiments, the loss of link A (Link loss A) is adjusted by VOA 1 placed between an ONU and an optical amplifier with XGM-ALC. The loss of link B (Link loss B) value is also adjusted by VOA 2 placed between an optical amplifier with XGM-ALC and an OLT. XGM-ALC can mitigate overload in the receiver and expand the dynamic range in the access span regardless of the link loss of the trunk span in an optically-amplified PON system. 


\section{Experimental results and discussion}

To estimate the allowable link loss of an optically-amplified PON system, we evaluate the characteristics of the XGM-ALC output. Figure 2 (a) shows the measured extinction ratio and output power at each wavelength. Here, the input power of the EDFAs is defined as $P_{i n}$. In our experiments, the $P_{i n}$ values are adjusted to $-25 \mathrm{dBm}$ (weak signal) and $-8 \mathrm{dBm}$ (strong signal), respectively. With a weak signal, the extinction ratio and output power of the XGM-ALC are constantly controlled at each wavelength. On the other hand, with a strong signal, the extinction ratios of the XGM-ALC output at longer upstream wavelengths are higher than at shorter upstream wavelengths because the SOA gain peak is 1584 to $1598 \mathrm{~nm}$ and wavelength conversion occurs easily. On the other hand, the XGM-ALC output power is constantly controlled at each wavelength.

We propose a simple method for evaluating the allowable link loss of an optically-amplified PON system by using the optical modulation amplitude (OMA) as a parameter [9]. The OMA means the energy difference between the mark and space levels and is given by

$$
O M A[d B m]=10 \log _{10}\left(2 P_{\text {out }} \frac{r_{\text {out }}-1}{r_{\text {out }}+1}\right) .
$$

(a)

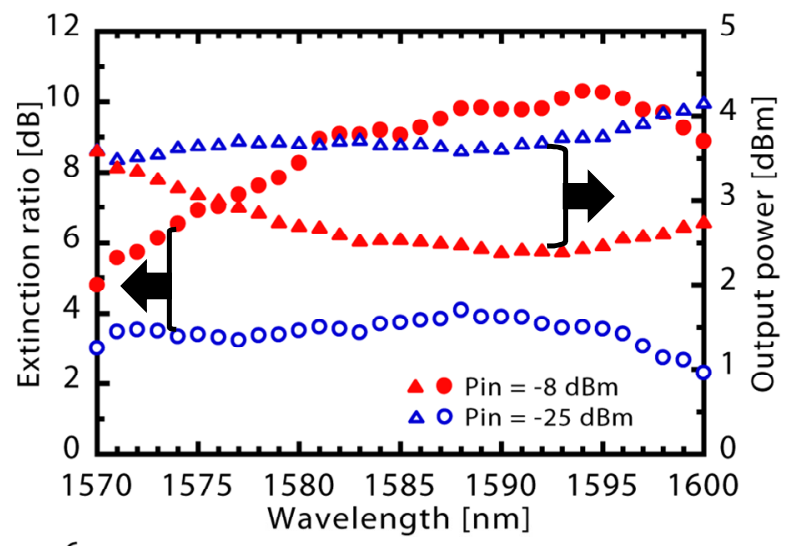

(b)

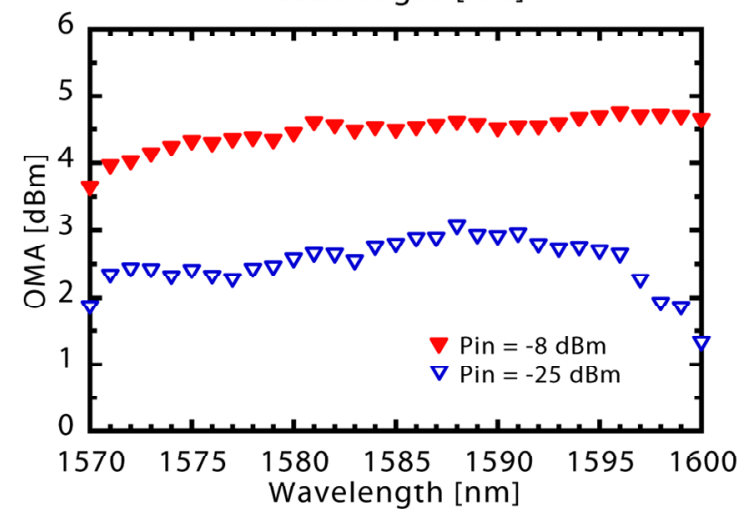

Fig. 2. (a) Wavelength versus extinction ratio and output power of XGM-ALC output signal when Pin is -8 and $-25 \mathrm{dBm}$. (b) Wavelength versus OMA of XGM-ALC output signals when Pin is -8 and $-25 \mathrm{dBm}$. 
Where $P_{\text {out }}$ and $r_{\text {out }}$ are the average power and extinction ratio of the XGMALC output signal, respectively. Figure 2 (b) shows the OMA of the XGMALC output under each condition. The OMA is a constantly controlled $2.5 \mathrm{dBm}$ at a $P_{\text {in }}$ of $-8 \mathrm{dBm}$ and $4.5 \mathrm{dBm}$ at a $P_{\text {in }}$ of $-25 \mathrm{dBm}$ from 1572 to $1596 \mathrm{~nm}$. The maximum allowable link loss B can be estimated from the OMA, and is given by

$$
\text { Link loss } B[d B]=(O M A-3)-10 \log _{10}\left(P_{\text {sen }}\left(r_{i n}\right) \frac{r_{i n}-1}{r_{i n}+1}\right) .
$$

Where $P_{\text {sen }}\left(r_{i n}\right)$ and $r_{i n}$ are the sensitivity of the OLT receiver and the extinction ratio of the detected signal, respectively. The first term converts the OMA value to the average optical power. The second term defines the receiver sensitivity when the extinction ratio is infinity. The maximum allowable link loss $\mathrm{B}$ is estimated to be $35.8 \mathrm{~dB}$ at a $P_{\text {in }}$ of $-8 \mathrm{dBm}$ and $33.8 \mathrm{~dB}$ at a $P_{\text {in }}$ of $-25 \mathrm{dBm}$.

To confirm the ability of the XGM-ALC to expand the dynamic range in optically-amplified PON systems, we measured the BERs while varying the values of both link loss A and B. Figure 3 (a) shows the operating area of an optically-amplified PON system using XGM-ALC. The operating area is surrounded by dashed lines that plot points within the error free operation region at each wavelength. At a link loss $\mathrm{A}$ of $8 \mathrm{~dB}\left(P_{\text {in }}\right.$ of $\left.-8 \mathrm{dBm}\right)$, the

(a)

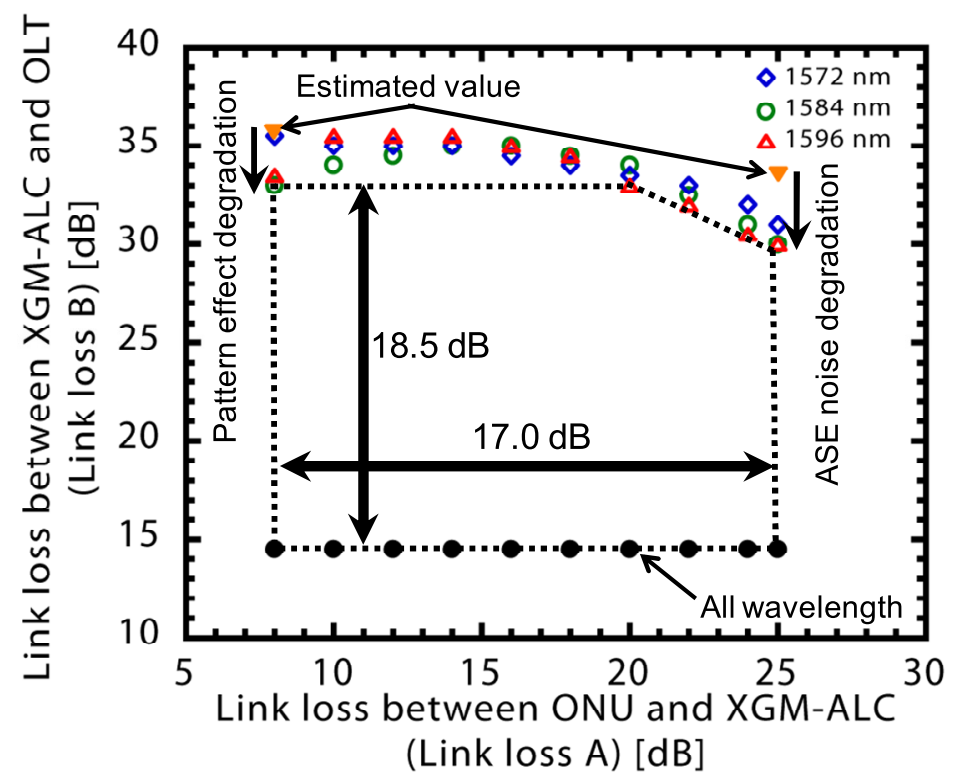

(b-1)

(b)

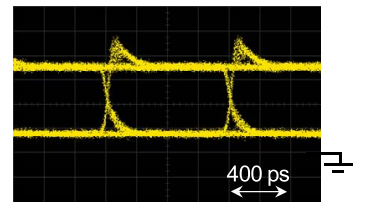

$(b-2)$

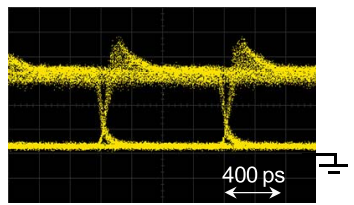

(b-3)

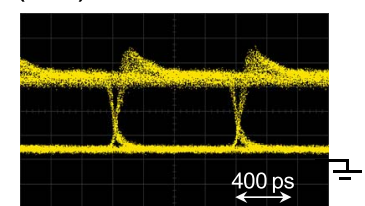

Fig. 3. (a) Allowable link loss $\mathrm{B}$ against Link loss A. (b) Measured eye diagrams of XGM-ALC output at each wavelength when Pin of $-8 \mathrm{dBm}$. (b-1) $1572 \mathrm{~nm}$. (b-2) $1584 \mathrm{~nm}$. (b-3) $1596 \mathrm{~nm}$. 
allowable link loss B at 1572, 1584 and $1596 \mathrm{~nm}$ and the estimated value are 35.5, 33.0, 33.5 and $35.8 \mathrm{~dB}$, respectively. The XGM-ALC outputs at 1584 and $1596 \mathrm{~nm}$ have deteriorated from the estimated value. Figure 3 (b-1), (b2) and (b-3) show eye diagrams of the XGM-ALC output at 1572, 1584 and $1596 \mathrm{~nm}$, respectively, when the link loss A is $8 \mathrm{~dB}$. As shown in each eye diagram, the mark levels in Fig. 3 (b-2) and (b-3) are slightly degraded compared with that in Fig. 3 (b-1) owing to the pattern effect in the SOA. This is because the pattern effect is easily induced around the gain peak and the SOA has a gain peak at 1584 to $1598 \mathrm{~nm}$. On the other hand, at a link loss A of $25 \mathrm{~dB}\left(P_{\text {in }}\right.$ of $\left.-25 \mathrm{dBm}\right)$, the allowable link losses B at 1572, 1584 and $1596 \mathrm{~nm}$ and the estimated value are $31.0,30.0,30.0$ and $33.8 \mathrm{~dB}$, respectively. The XGM-ALC outputs at all wavelengths have deteriorated from the estimated value. This is because amplified spontaneous emission (ASE) noise from the EDFAs induces degradation in the OLT receiver sensitivity.

In Fig. 3 (a), we achieved a dynamic range in link loss $\mathrm{B}$ of $18.5 \mathrm{~dB}$ against link loss B between 8.0 and $20.0 \mathrm{~dB}$. The allowable link loss A can be expanded between 8.0 and $25.0 \mathrm{~dB}$ when the dynamic range in link loss $\mathrm{B}$ is reduced to $15.5 \mathrm{~dB}$. The maximum loss budget is $55.0 \mathrm{~dB}$.

\section{Conclusion}

We investigated the upstream transmission operating area in an opticallyamplified PON system utilizing the XGM-ALC technique. The XGM-ALC mitigated the receiver overload in the OLT, which helped to expand the operating area of the system. We proposed a simple method for evaluating allowable link budgets by using the OMA to wavelength converted signals. We compared experimental results with our estimations and showed that the allowable link losses of the trunk span against strong signal inputs around the SOA gain peak wavelengths deteriorated from our estimations owing to the pattern effect in the SOA. The allowable link losses of the trunk span against weak signal inputs also deteriorated from our estimations owing to the ASE noise of the optical amplifiers we used. Nevertheless, the experimental results showed that the XGM-ALC could achieve the allowable dynamic range in a trunk span of $18.5 \mathrm{~dB}$ against the link loss range of the access span between 8.0 and $20.0 \mathrm{~dB}$ across a wavelength range of $24 \mathrm{~nm}$. The link loss range of the access span could be expanded between 8.0 and $25.0 \mathrm{~dB}$ if the system accepted a reduction in the dynamic range in the trunk span to $15.5 \mathrm{~dB}$. The maximum link budget of the system was $55.0 \mathrm{~dB}$.

\section{Acknowledgments}

This work was partly supported by a project of the National Institute of Information and Communications Technology (NICT) of Japan. 